\title{
Cynomorium songaricum extract enhances novel object recognition, cell proliferation and neuroblast differentiation in the mice via improving hippocampal environment
}

Dae Young Yoo', Jung Hoon Choi ${ }^{2 *}$, Woosuk Kim', Hyo Young Jung ${ }^{1}$, Sung Min Nam¹, Jong Whi Kim', Yeo Sung Yoon ${ }^{1}$, Ki-Yeon Yoo ${ }^{3}$, Moo-Ho Won ${ }^{4}$ and In Koo Hwang ${ }^{1 *}$

\begin{abstract}
Background: Cynomorium songaricum Rupr. (CS) has been used as a medicine to treat many diseases as well as to alleviate age-related issues, such as memory impairment, dementia, and stress. In this study, we assessed the effects of Cynomorium songaricum extract (CSE) on the novel object recognition, cell proliferation and neuroblast differentiation in the dentate gyrus of mice by using 5-bromodeoxyuridine (BrdU) and polysialylated neural cell adhesion molecule (PSA-NCAM). We also measured serum corticosterone levels to assess its correlation with neurogenesis and stress.
\end{abstract}

Methods: Male C57BL/6 J mice were divided into 3 groups: vehicle-treated, 40 mg/kg CSE-treated, and 100 mg/kg CSE-treated. The vehicle and CSE were given to mice once a day for 3 weeks. BrdU was injected twice a day for 3 days to label newly generated cells.

Results: Administration of CSE significantly increased the preferential exploration of new objects in these mice. In addition, administration of CSE decreased serum levels of corticosterone. BrdU-positive cells as well as brain-derived neurotrophic factor (BDNF) mRNA expression in the dentate gyrus were higher in the CSE-treated groups than in the vehicle-treated group. PSA-NCAM-positive neuroblasts and their well-developed tertiary dendrites were also significantly increased by the treatment of CSE. These effects were prominent at the higher dosage than at the lower dosage.

Conclusion: These results suggest that administration of CSE increases cell proliferation and neuroblast differentiation in the dentate gyrus of mice by reducing serum corticosterone levels and increasing BDNF levels in this area.

Keywords: Cynomorium songaricum extract, Hippocampus, 5-bromodeoxyuridine, Polysialylated neural cell adhesion molecule, Corticosterone

\footnotetext{
* Correspondence: jhchoi@kangwon.ac.kr; vetmed2@snu.ac.kr

${ }^{2}$ Department of Anatomy, College of Veterinary Medicine, Kangwon National University, Chuncheon 200-701, South Korea

'Department of Anatomy and Cell Biology, College of Veterinary Medicine, and Research Institute for Veterinary Science, Seoul National University, Seoul 151-742, South Korea

Full list of author information is available at the end of the article
} 


\section{Background}

Findings of recent research suggest that neurogenesis occurs throughout the lifetime in the adult mammalian brain [1-4]. There are 2 discrete neurogenic regions in the adult brain; the dentate gyrus is one of them [5]. The dentate gyrus is closely related to learning and memory $[6,7]$, and it has been reported that hippocampal neurogenesis is associated with neurological problems, such as depression and Alzheimer's disease [8,9]. In the dentate gyrus, new neurons are produced from progenitor cells in the subgranular zone and migrate into the granule cell layer [2]. Neurogenesis in the adult dentate gyrus is highly labile [10] and is affected by many exogenous and endogenous factors $[11,12]$.

Cynomorium songaricum Rupr. (CS) is a well-known root-parasitic plant and is distributed throughout northwest China [13]. Cynomorium songaricum extract (CSE) has been widely used as Chinese herbal remedy for problems such as sexual dysfunction, renal disease, and lumbar weakness [14]. Moreover, it has been reported that CS induces proliferation of undifferentiated spermatogonia with glial cell-derived neurotrophic factor (GDNF) enhancement [15]. Chemically, CS consists of organic acids, triterpenes, polysaccharides, steroidal compounds, and flavonoids [16]. CSE has been shown to suppress age-related learning impairments in aged flies by reducing hydroperoxide levels and increasing antioxidants [14]. Among the chemical compounds in CS, flavonoids have antioxidant effects, and certain types of flavonoids are involved in neuroprotection and hippocampal neurogenesis [17-19]. It has also been reported that CSE modulates $\gamma$-aminobutyric acid (GABA) and monoamine transporters, both of which are involved in hippocampal neurogenesis [13].

Novel object recognition tasks are non-aversive learning paradigms, which rely on spontaneous exploratory behavior in experimental animals. Therefore, we investigated the effects of CSE on novel object recognition and hippocampal neurogenesis by using 5-bromodeoxyuridine (BrdU) for cell proliferation and polysialylated neural cell adhesion molecule (PSA-NCAM) for detecting developing granule neurons in mice. We also measured serum corticosterone and brain-derived neurotrophic factor (BDNF) mRNA expression levels to elucidate the possible effect of CSE on neurogenesis.

\section{Methods}

\section{Preparation of CSE}

Cynomorium songaricum Rupr. was purchased from Kyung-dong market (Seoul, South Korea). The plants were authenticated by two oriental medical doctors and the voucher specimen was deposited in our laboratory (deposition number: 2012-028). The plants (100 g) were chopped and blended using a blender and soaked in $2 \mathrm{~L}$ of $80 \%$ ethanol and refluxed at $20^{\circ} \mathrm{C}$ for $2 \mathrm{~h}$ three times. The insoluble materials were removed through centrifugation at $10,000 \times g$ for $30 \mathrm{~min}$, and the resulting supernatant was concentrated and freeze-dried to yield a powder (yield: 13.2\%). Before each experiment, the dried extract was dissolved in distilled and deionized water.

$$
\begin{aligned}
& \mathrm{CSE} \longrightarrow \\
& \text { BrdU } \stackrel{21 \mathrm{~d} \text { (b.i.d.) }}{\longrightarrow}
\end{aligned}
$$

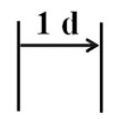

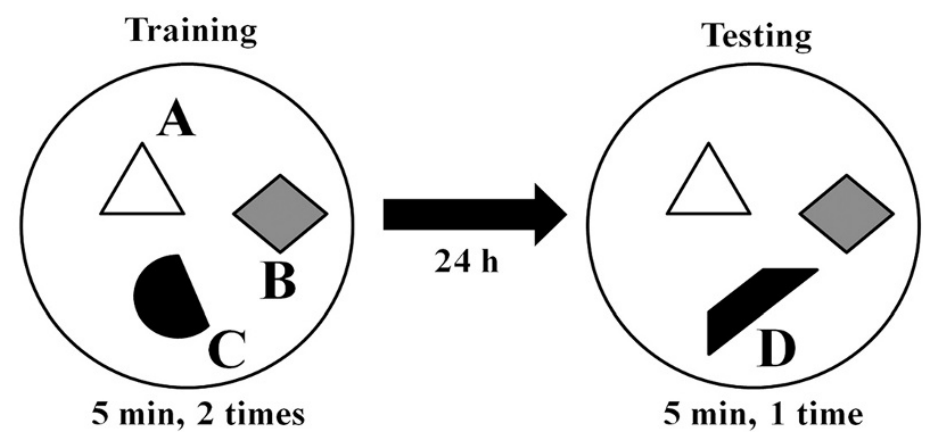

Figure 1 Study design and novel object recognition task. Vehicle or CSE were orally administered to mice using a feeding needle once a day for 21 days and BrdU was treated twice a day for 3 days from the day of the first CSE treatment. At 20 days after CSE treatment, mice were allowed to explore three different objects (A, B and C) for 5 min trials in an open field. $24 \mathrm{~h}$ after open field trial, novel object recognition test was performed and exploration times were recorded for each object. 


\section{Experimental animals}

The progeny of male C57BL/6 J mice were purchased from the Jackson Laboratory Co. Ltd (Bar Harbor, ME). Six-week-old mice were used in this study. The mice were housed in a conventional state under adequate controlled temperature $\left(22^{\circ} \mathrm{C}\right)$, humidity $(55 \%)$, 12-h light/ 12-h dark cycle, and provided with free access to food and tap water. The procedures for the care and handling of animals conformed to guidelines that are in compliance with current international laws and policies (NIH Guide for the Care and Use of Laboratory Animals, NIH Publication No. 85-23, 1985, revised 1996), and the experimental protocol was approved by the Institutional Animal Care and Use Committee (IACUC) of Seoul National University (approval no. SNU-110527-2). All of the experiments were conducted in a way as to minimize the number of animals used and the suffering caused by the procedures used in the present study.

\section{Treatment with CSE and BrdU}

Mice were randomly divided into the 3 groups: vehicletreated group, 40 and $100 \mathrm{mg} / \mathrm{kg}$ CSE-treated groups ( $n=12$ in each group). Vehicle or CSE were orally administered to mice using a feeding needle once a day for 21 days and the animals were sacrificed at immediately after the novel object recognition test. These schedules were adopted because PSA-NCAM is a marker for differentiated neuroblasts expressed in immature neurons from only 1 to 21 days of cell age. In order to determine the integration of new neurons generated in the adult brain, the animals in the vehicle-treated group $(n=7)$ and the $40 / 100 \mathrm{mg} / \mathrm{kg}$ CSE-treated groups $(n=7$ in each group) were treated with $50 \mathrm{mg} / \mathrm{kg} 5$-bromodeoxyuridine (BrdU, Sigma, St. Louis, MO) twice a day for 3 days from the day of the first CSE treatment.

\section{Novel object recognition test}

At 20 days after CSE treatment, mice $(n=12$ in each group) were placed in an open field and allowed to explore three different objects (A, B and C) for 5 min trials and this was repeated once. Object $C$ was replaced by a novel object (D) $24 \mathrm{~h}$ after open field trial and the mice were allowed to explore for $5 \mathrm{~min}$ trial (Figure 1). Exploration times were recorded for each object and expressed as a percentage of total exploration time.

\section{Blood sampling and measurement of corticosterone levels}

For blood sampling, the animals ( $n=12$ in each group) were anesthetized with intraperitoneal injection of $1 \mathrm{~g} / \mathrm{kg}$ urethane (Sigma, St. Louis, MO), and blood samples were collected from each mouse by cardiac puncture before tissue sampling for immunohistochemistry and PCR analysis. Serum was separated from the blood by centrifugation at
$1,100 \mathrm{~g}$ for $15 \mathrm{~min}$ at $4^{\circ} \mathrm{C}$ and serum $(50 \mu \mathrm{L})$ was added to $5 \mathrm{~mL}$ of methylene chloride and incubated at room temperature for $10 \mathrm{~min}$. After filtration with cheesecloth, the mixture was combined with $2.5 \mathrm{~mL}$ of fluorescence reagent (7:3, sulfuric acid/absolute ethanol), vortexed vigorously and incubated for $30 \mathrm{~min}$ at room temperature. After centrifugation, the lower layer was measured using a spectrophotometer (excited wavelength, $475 \mathrm{~nm}$; emission wavelength, $530 \mathrm{~nm}$ ).

\section{Tissue processing for histology}

For histology, the animals ( $n=7$ in each group) were used after blood sampling. The animals were perfused transcardially with $0.1 \mathrm{M}$ phosphate-buffered saline (PBS, $\mathrm{pH}$ 7.4) followed by $4 \%$ paraformaldehyde in $0.1 \mathrm{M}$ phosphate-buffer. The brains were removed and postfixed in the same fixative for $4 \mathrm{~h}$. The brain tissues were cryoprotected by infiltration with $30 \%$ sucrose overnight. Thirty- $\mu$ m-thick brain sections in coronal plane were

\section{(A) Training day}

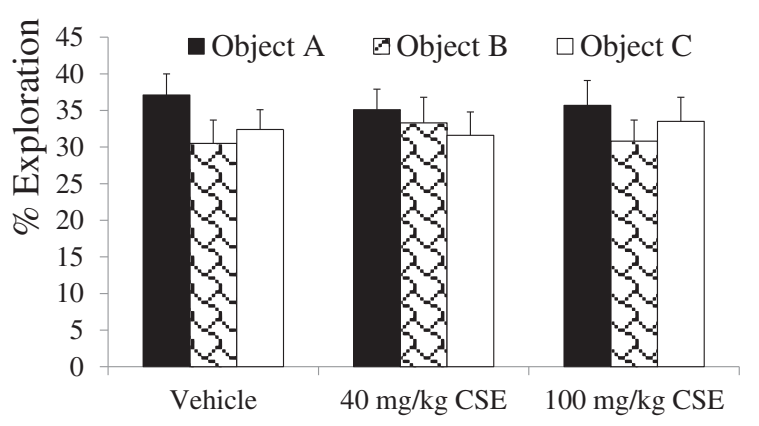

(B) Testing day

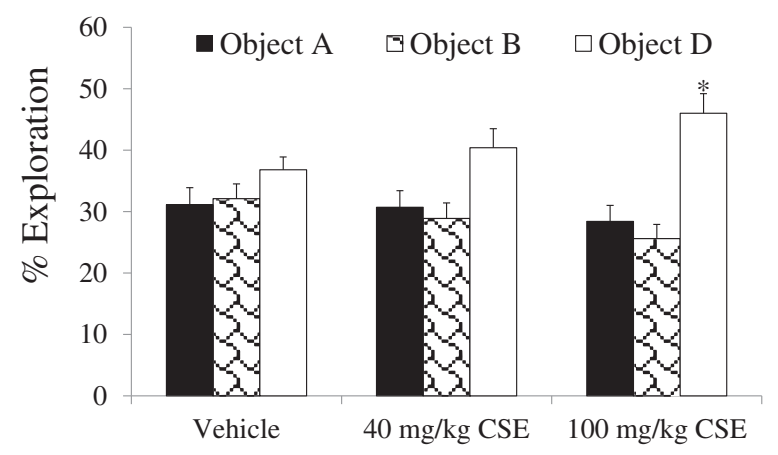

Figure 2 Effects of CSE on novel object recognition test. Preference for exploring novel objects in vehicle-treated, $40 \mathrm{mg} / \mathrm{kg}$ CSE-treated, and $100 \mathrm{mg} / \mathrm{kg}$ CSE-treated mice ( $n=12$ per group; ${ }^{*} P<0.05$, versus vehicle-treated group). Data are presented as the exploration time for each object ( $A, B$, or $C$, where $C$ is replaced by $D$ on the testing day) as a percentage of the total exploration time. On the training day, the animals do not show preference to explore any particular object. On the testing day, CSE-treated mice preferentially explore the novel object D. All data are shown as \% exploration \pm SEM. 


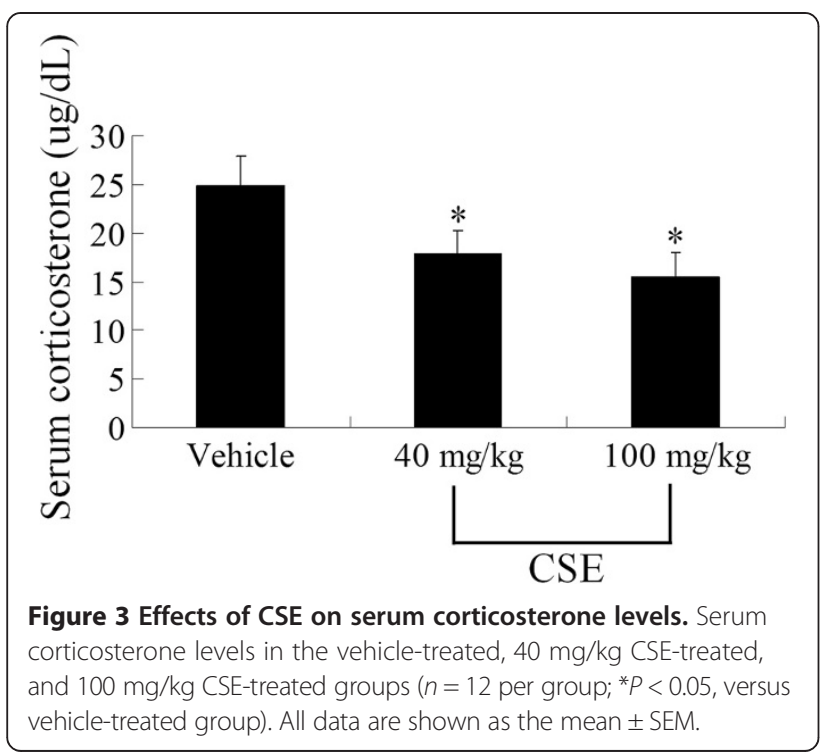

serially cut using a cryostat (Leica, Wetzlar, Germany). The sections were collected into six-well plates containing PBS for further process.

\section{Immunohistochemistry for BrdU and PSA-NCAM}

To obtain the accurate data for immunohistochemistry, the free-floating sections were carefully processed under the same conditions. The tissue sections were selected between $-1.46 \mathrm{~mm}$ and $-2.46 \mathrm{~mm}$ posterior to the bregma in reference to the mouse atlas for each animal [20]. The sections were sequentially treated with $0.3 \%$ hydrogen peroxide $\left(\mathrm{H}_{2} \mathrm{O}_{2}\right)$ in PBS for $30 \mathrm{~min}$ and $10 \%$ normal goat serum in $0.05 \mathrm{M}$ PBS for $30 \mathrm{~min}$. For BrdU immunostaining, DNA was first denatured by incubating the sections in $50 \%$ formamide $/ 2 \times$ standard saline citrate at $65^{\circ} \mathrm{C}$ for $2 \mathrm{~h}$ and in $2 \mathrm{~N} \mathrm{HCL}$ at $37^{\circ} \mathrm{C}$ for $30 \mathrm{~min}$. They were next incubated with diluted mouse anti-PSA-NCAM (1:200; Chemicon, Temecula, CA) or rat anti-BrdU (1:200, BioSource International, Camarillo, CA) overnight at room temperature and subsequently exposed to biotinylated goat anti-mouse IgG (1:200; Vector, Burlingame, CA) or FITC-conjugated anti-rat IgG (1:200; Jackson ImmunoResearch, West Grove, PA). For PSA-NCAM staining, the sections were incubated with streptavidin peroxidase complex (1:200; Vector), visualized with reaction to 3,3'-diaminobenzidinetetrachloride (Sigma, St. Louis, MO) in $0.1 \mathrm{M}$ Tris- $\mathrm{HCl}$ buffer (pH 7.2) and mounted on gelatincoated slides.

In order to quantitatively analyze BrdU- and PSANCAM-positive cells, 10 sections per animal selected in the hippocampus at the level of -1.46 to $-2.46 \mathrm{~mm}$ posterior to the Bregma. BrdU- and PSA-NCAM-positive cells were calculated using an image analyzing system equipped with a computer-based CCD camera (software: Optimas 6.5, CyberMetrics, Scottsdale, AZ). The cell counts from all of the sections of all of the mice were averaged.

\section{BDNF mRNA levels in the dentate gyrus}

For PCR analysis, the animals ( $n=5$ in each group) were used in this study after blood sampling. The dentate
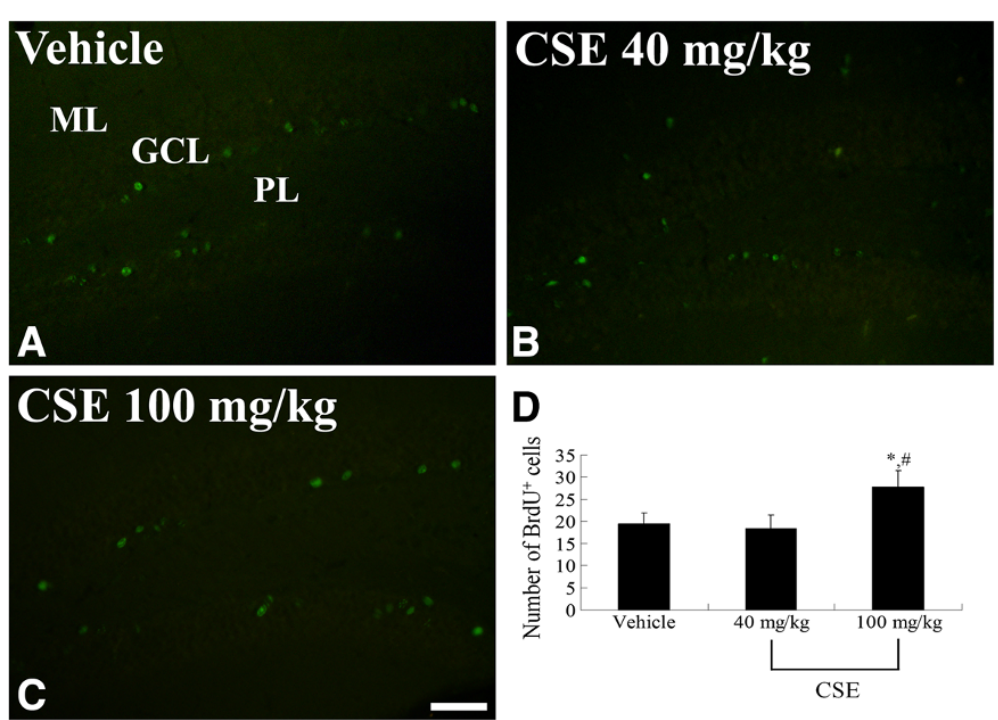

Figure 4 Effects of CSE on cell proliferation. BrdU immunofluorescence in the dentate gyrus of the vehicle-treated (A), $40 \mathrm{mg} / \mathrm{kg}$ CSE-treated (B), and $100 \mathrm{mg} / \mathrm{kg}$ CSE-treated (C) groups. BrdU-positive cells are significantly higher in the $100 \mathrm{mg} / \mathrm{kg}$ CSE-treated group than in the vehicletreated and 40 mg/kg CSE-treated groups. GCL: granule cell layer; ML: molecular layer; PoL: polymorphic layer. Scale bar $=50 \mu \mathrm{m}$. D: The number of BrdU-positive cells in the dentate gyrus of the vehicle-treated, $40 \mathrm{mg} / \mathrm{kg}$ CSE-treated, and $100 \mathrm{mg} / \mathrm{kg}$ CSE-treated groups ( $n=7$ per group; ${ }^{*} P<0.05$, versus vehicle-treated group; ${ }^{\#} P<0.05$, versus the $40 \mathrm{mg} / \mathrm{kg}$ CSE-treated group). All data are shown as the mean \pm SEM. 

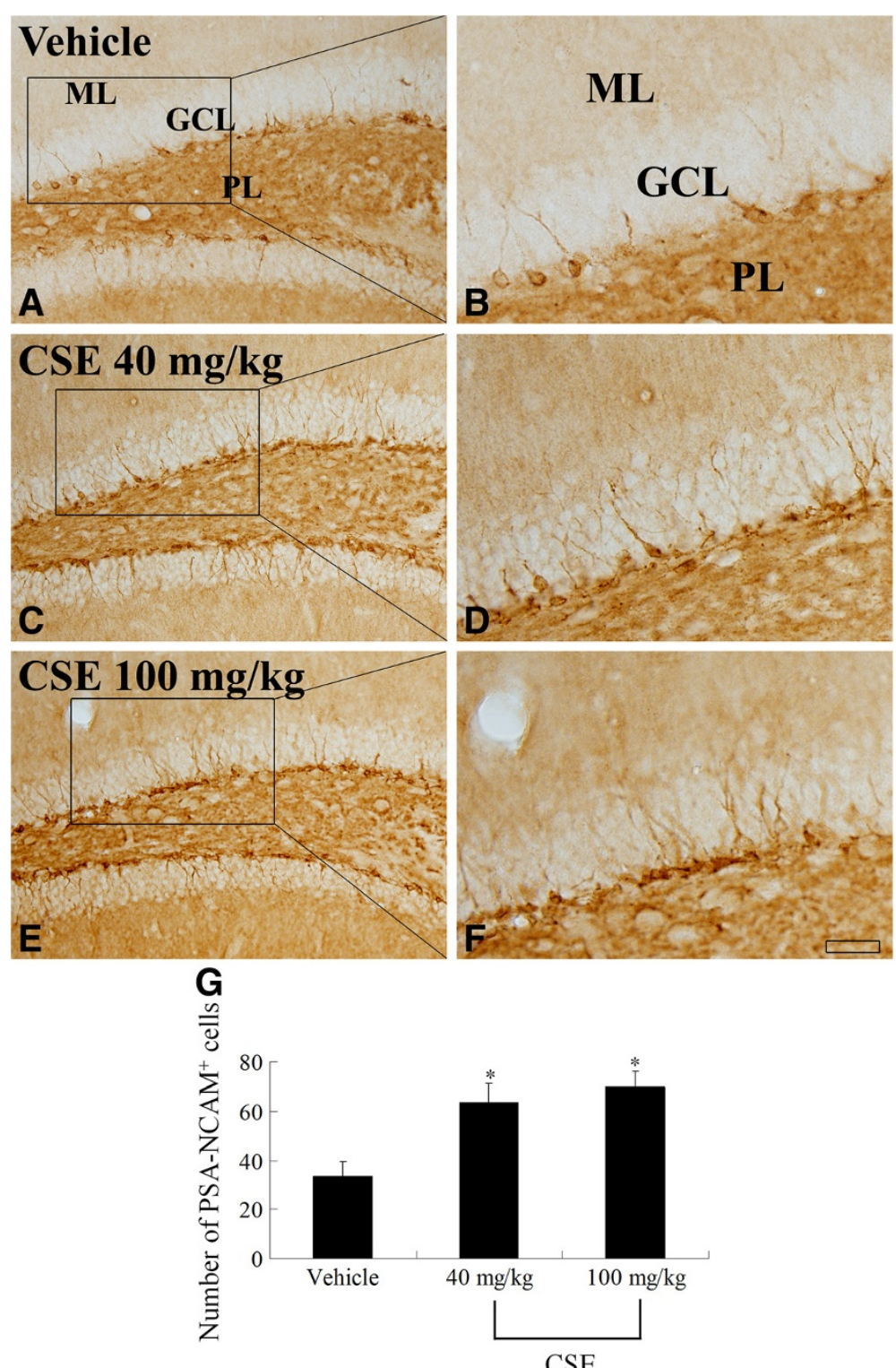

Figure 5 Effects of CSE on neuroblast differentiation. PSA-NCAM immunohistochemistry in the dentate gyrus of the vehicle-treated (A, B), $40 \mathrm{mg} / \mathrm{kg}$ CSE-treated (C, D), and $100 \mathrm{mg} / \mathrm{kg}(\mathbf{E}, \mathbf{F})$ CSE-treated groups. Compared with the vehicle-treated group, the CSE-treated group shows a higher number of PSA-NCAM-immunoreactive neuroblasts with well-developed dendrites. GCL: granule cell layer; ML: molecular layer; PoL: polymorphic layer. Scale bar $=50 \mu \mathrm{m}(\mathbf{A}, \mathbf{C}$, and E), $25 \mu \mathrm{m}$ (B, D, and F). G: The number of PSA-NCAM-positive neuroblasts in the dentate gyrus of the vehicle-treated, $40 \mathrm{mg} / \mathrm{kg}$ CSE-treated, and $100 \mathrm{mg} / \mathrm{kg}$ CSE-treated groups ( $n=7$ per group; ${ }^{*} P<0.05$, versus vehicle-treated group). All data are shown as the mean \pm SEM.

gyrus was dissected out from brain tissues. RNA extraction was performed using a total RNA isolation kit (Macherney-Nagel). Spectrophotometric measurements were conducted using the Nanodrop Spectrophotometer (Nanodrop Technologies Wilmington, DE, USA) to determine RNA concentration and purity. A high capacity cDNA archive kit (Applied Biosystems) was used to reverse transcribe the equalized RNA samples. Quantitative real-time PCR (qPCR) was performed with
50 ng cDNA using custom-designed gene-expression assays for BDNF.

Gene expression of targets was assessed using Taqman gene expression assays (Applied Biosystems, UK) containing specific target primers, and FAM-labeled MGB target probes. $\beta$-actin gene expression was used to normalize gene expression between samples, and was quantified using a $\beta$-actin endogenous control gene expression assay containing specific primers, and a VIC-labeled MGB 
probe for rat $\beta$-actin. Analysis was performed using the $\triangle \triangle \mathrm{CT}$ method. The primers used were as follows: $5^{\prime}-$ GTGACAGTATTAGCGAGTGGG -3' (forward) and 5' CTAGGGCGGCCCACGATGGA-3' (reverse) for BDNF and 5'-GCACCACACCTTCTA CAATG-3' (forward) and 5 '-TGCTTGCTGATCCACATCTG-3' (reverse) for $\beta$-actin.

\section{Statistical analysis}

The data shown here represent the means of experiments performed for each experimental area. Differences among the means were statistically analyzed by one-way analysis of variance followed by Tukey's multiple range method in order to elucidate differences between the vehicle- and CSE-treated groups.

\section{Results}

\section{Effects of CSE on object recognition}

During the training period, all groups spent a similar fraction of time exploring the 3 different objects. In addition, there were no significant changes in total exploration time. During the testing period, vehicle-treated mice showed significant increases in the amount of time spent exploring object D. The administration of CSE significantly increased the time spent exploring object $\mathrm{D}$ in a dose-dependent manner and the time spent exploring object D in $100 \mathrm{mg} / \mathrm{kg}$ CSE-treated group was significantly increased compared to that in the vehicle-treated group (Figure 2).

\section{Effects of CSE on serum corticosterone levels}

To elucidate the possible mechanism of CSE action on neurogenesis, serum corticosterone levels were measured in each group. In the vehicle-treated group, mean serum corticosterone was $24.8 \mu \mathrm{g} / \mathrm{dL}$. In the $40 \mathrm{mg} / \mathrm{kg}$ CSE-treated group, mean serum corticosterone level was $17.8 \mu \mathrm{g} / \mathrm{dL}$, which was significantly lower than that in the vehicle-treated group. In the $100 \mathrm{mg} / \mathrm{kg}$ CSE-treated group, mean serum corticosterone level was $15.4 \mu \mathrm{g} / \mathrm{dL}$, which indicated that the reduction was dose-dependent (Figure 3).

\section{Effects of CSE on cell proliferation}

Immunohistochemical staining for BrdU was performed to confirm the effect of CSE on cell proliferation in the dentate gyrus (Figure 4). In the vehicle group, a few BrdU-positive cells were detected in the dentate gyrus (Figure 4A). Compared to the vehicle-treated group, the $40 \mathrm{mg} / \mathrm{kg}$ CSE-treated group showed little difference in the number of BrdU-positive cells (Figure 4B). However, the number of BrdU-positive cells in the dentate gyrus was significantly higher in the $100 \mathrm{mg} / \mathrm{kg}$ CSE-treated group than in the vehicle-treated and $40 \mathrm{mg} / \mathrm{kg}$ CSEtreated groups (Figure 4C and D).

\section{Effects of CSE on neuroblast differentiation}

To observe neuroblast differentiation in the subgranular zone of mouse dentate gyrus, we performed immunohistochemical staining using antibody against PSA-NCAM (Figure 5). In the vehicle-treated group, PSA-NCAMpositive neuroblasts with poorly developed dendrites were noted in the subgranular zone (Figure 5A and B). The number of PSA-NCAM-positive neuroblasts was significantly higher in the 40 and $100 \mathrm{mg} / \mathrm{kg}$ CSE-treated groups than in the vehicle-treated group. Moreover, these neuroblasts had well-developed dendrites extending to the molecular layer (Figure 5C, D, E, F, and G).

\section{Effects of CSE on BDNF mRNA expression}

To investigate the possible mechanisms underlying the observed cognitive improvements, we tested the dentate gyri of mice for BDNF expression. BDNF mRNA expression in the 40 and $100 \mathrm{mg} / \mathrm{kg}$ CSE-treated groups was significantly increased by 1.40 and 1.49 folds compared to that in the vehicle-treated group, respectively (Figure 6).

\section{Discussion}

In the present study, we observed the behavioral preferences of mice to novel objects after CSE treatment; this behavioral paradigm exploits the ability of the mice to explore novel objects over familiar ones during simultaneous presentation and has been employed to evaluate recognition memory [21]. During training periods, mice in all groups did not show any preferences among the 3 different objects. However, during the test periods, CSEtreated mice showed strong preferences for the novel object, while vehicle-treated mice displayed a much lesser preference for it. The result of the behavioral test is

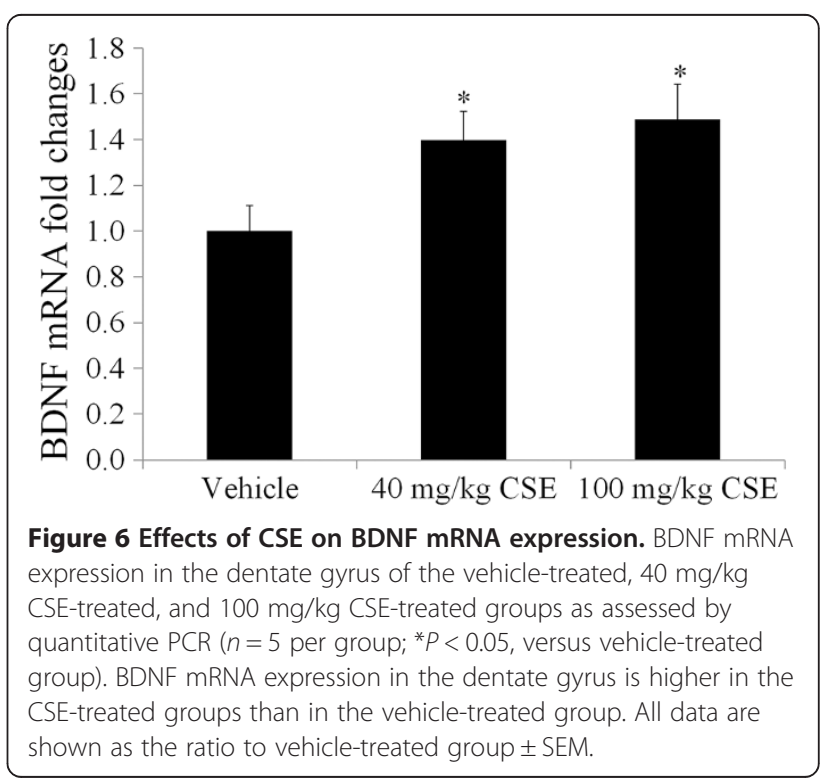


supported by changes of serum corticosterone and BDNF expression measured in this study.

We checked serum corticosterone and BDNF mRNA levels to elucidate the possible mechanisms for hippocampal neurogenesis. CSE treatment decreased serum corticosterone levels in general, and the corticosterone level in the $100 \mathrm{mg} / \mathrm{kg}$ CSE-treated group was lower than that in the $40 \mathrm{mg} / \mathrm{kg}$ CSE-treated group. It has been reported that corticosteroid hormones regulate the proliferation, survival, and death of granule cells in the dentate gyrus [22-24]. Additionally, corticosterone is known to be associated with cognitive impairment and has detrimental effects on LTP in the dentate gyrus [25-27]. Moreover, corticosterone acts on hippocampal BDNF expression through the exon IV promoter [28], which is required for the enhancement of hippocampal neurogenesis [29].

Next, we morphologically observed the effects of CSE on cell proliferation and neuroblast differentiation in the dentate gyrus. Treatment with CSE increased both BrdUpositive cells and PSA-NCAM-positive neuroblasts. These neuroblasts displayed well-developed dendrites, indicating that CSE may be involved in neuroblast maturation. Therefore, treatment with CSE can possibly modulate synaptic plasticity by increasing cell proliferation and neuroblast differentiation in the subgranular zone of the dentate gyrus. It has been reported that functional and morphological changes in the synapse induce altered neuronal plasticity in the mammalian brain [30,31]. Additionally, CSE is known to act as an inhibitor of serotonin and GABA transporters, both of which are crucial for limiting monoaminergic and GABAergic activity [13,32,33]. GABA is the principal inhibitory neurotransmitter in the brain and plays an important role in CNS development and plasticity [34], and serotonin is an important modulator of hippocampal neurogenesis [35]. GABA also significantly increases recognition and working memory in rats [36].

Administration of CSE significantly increased BDNF mRNA expression in the dentate gyrus homogenates. BDNF, synthesized locally in the dendrites of granule cells, promotes differentiation and maturation of progenitor cells in the subgranular zone of dentate gyrus by enhancing GABA release [37]. Here, the increase of tertiary dendrites of the neuroblasts, stained with PSA-NCAM, may be associated with BDNF increase in the dentate gyrus.

Recently, many researchers have explored the mechanism of action and function of CSE in the brain. CSE has been shown to attenuate $A \beta$-induced cell death and protect against superoxide anion-induced cell death [38,39]. In addition, CSE exhibits anti-aging effects by increasing telomere length in the brain of the D-galactose-induced aging mice [40]. In this study, we confirmed that CSE administration influences hippocampal neurogenesis and cognitive memory by changing BDNF and serum corticosterone levels.

\section{Conclusion}

Treatment with CSE significantly increased preference for the novel object in the novel object recognition test and enhanced hippocampal neurogenesis in the mouse dentate gyrus. Changes of the BDNF and serum corticosterone levels were also detected and may be closely associated with novel object recognition and hippocampal neurogenesis. These results suggest that CSE has the potential for enhancing hippocampal plasticity and can be used to people who have problems in hippocampal memory.

\section{Competing interests}

The authors declare that they have no competing interests.

\section{Authors' contributions}

DYY, JHC, WK, HYJ, SMN, JWK, YSY, and IKH conceived the study, designed and conducted the experiments, and drafted the manuscript. KYY and MHW participated in designing and discussing the study. All authors have read and approved the final manuscript.

\section{Acknowledgements}

This work was supported by Basic Science Research Program through the National Research Foundation of Korea (NRF) funded by the Ministry of Science, ICT \& Future Planning (2011-0013933).

\section{Author details}

${ }^{1}$ Department of Anatomy and Cell Biology, College of Veterinary Medicine, and Research Institute for Veterinary Science, Seoul National University, Seoul 151-742, South Korea. ${ }^{2}$ Department of Anatomy, College of Veterinary Medicine, Kangwon National University, Chuncheon 200-701, South Korea. ${ }^{3}$ Department of Oral Anatomy, College of Dentistry, Research Institute of Oral Sciences, Gangneung-Wonju National University, Gangneung 210-702, South Korea. ${ }^{4}$ Department of Neurobiology, School of Medicine, Kangwon National University, Chuncheon 200-701, South Korea.

Received: 9 September 2013 Accepted: 31 December 2013 Published: 7 January 2014

\section{References}

1. Paizanis E, Kelai S, Renoir T, Hamon M, Lanfumey L: Life-long hippocampal neurogenesis: environmental, pharmacological and neurochemical modulations. Neurochem Res 2007, 32:1762-1771.

2. Gage FH: Mammalian neural stem cells. Science 2000, 287:1433-1438.

3. Eriksson PS, Perfilieva E, Bjork-Eriksson T, Alborn AM, Nordborg C, Peterson DA, Gage FH: Neurogenesis in the adult human hippocampus. Nat Med 1998, 4:1313-1317.

4. Gould E, Reeves AJ, Fallah M, Tanapat P, Gross CG, Fuchs E: Hippocampal neurogenesis in adult Old World primates. Proc Natl Acad Sci USA 1999, 96:5263-5267.

5. Sohur US, Emsley JG, Mitchell BD, Macklis JD: Adult neurogenesis and cellular brain repair with neural progenitors, precursors and stem cells. Philos Trans R Soc Lond B Biol Sci 2006, 361:1477-1497.

6. Garthe A, Behr J, Kempermann G: Adult-generated hippocampal neurons allow the flexible use of spatially precise learning strategies. PLoS One 2009, 4:e5464.

7. Deng W, Aimone JB, Gage FH: New neurons and new memories: how does adult hippocampal neurogenesis affect learning and memory? Nat Rev Neurosci 2010, 11:339-350.

8. Sahay A, Hen R: Hippocampal neurogenesis and depression. Novartis Found Symp 2008, 289:152-160.

9. Mu Y, Gage FH: Adult hippocampal neurogenesis and its role in Alzheimer's disease. Mol Neurodegener 2011, 6:85.

10. Gould E, Cameron HA, Daniels DC, Woolley CS, McEwen BS: Adrenal hormones suppress cell division in the adult rat dentate gyrus. J Neurosci 1992, 12:3642-3650.

11. Lee $\mathrm{E}$, Son $\mathrm{H}$ : Adult hippocampal neurogenesis and related neurotrophic factors. BMB Rep 2009, 42:239-244. 
12. Van Praag H, Kempermann G, Gage FH: Running increases cell proliferation and neurogenesis in the adult mouse dentate gyrus. Nat Neurosci 1999, 2:266-270.

13. Zhao G, Wang J, Qin GW, Guo LH: Cynomorium songaricum extracts functionally modulate transporters of $\mathrm{\gamma}$-aminobutyric acid and monoamine. Neurochem Res 2010, 35:666-676.

14. Liu HP, Chang RF, Wu YS, Lin WY, Tsai FJ: The yang-tonifying herbal medicine Cynomorium songaricum extends lifespan and delays aging in Drosophila. Evid Based Complement Alternat Med 2012, 2012:735481.

15. Yang WM, Kim HY, Park SY, Kim HM, Chang MS, Park SK: Cynomorium songaricum induces spermatogenesis with glial cell-derived neurotrophic factor (GDNF) enhancement in rat testes. J Ethnopharmacol 2010 128:693-696.

16. Jiang ZH, Tanaka T, Sakamoto M, Jiang T, Kouno I: Studies on a medicinal parasitic plant: lignans from the stems of Cynomorium songaricum. Chem Pharm Bull 2001, 49:1036-1038.

17. Yu FR, Liu Y, Cui YZ, Chan EQ, Xie MR, McGuire PP, Yu FH: Effects of a flavonoid extract from Cynomorium songaricum on the swimming endurance of rats. Am J Chin Med 2010, 38:65-73.

18. Lee S, Kim DH, Lee DH, Jeon SJ, Lee CH, Son KH, Jung JW, Shin CY, Ryu JH, Oroxylin A: A flavonoid, stimulates adult neurogenesis in the hippocampal dentate gyrus region of mice. Neurochem Res 2010, 35:1725-1732

19. Gutierrez-Merino C, Lopez-Sanchez C, Lagoa R, Samhan-Arias AK, Bueno C, Garcia-Martinez V: Neuroprotective actions of flavonoids. Curr Med Chem 2011, 18:1195-1212.

20. Franklin KBJ, Paxinos G: The Mouse Brain in Stereotaxic Coordinates. San Diego: Academic Press; 1997.

21. Ennaceur A, Delacour J: A new one-trial test for neurobiological studies of memory in rats. 1: behavioral data. Behav Brain Res 1988, $31: 47-59$

22. Sloviter RS, Valiquette G, Abrams GM, Ronk EC, Sollas AL, Paul LA, Neubort S: Selective loss of hippocampal granule cells in the mature rat brain after adrenalectomy. Science 1989, 243:535-538.

23. Montaron MF, Piazza PV, Aurousseau C, Urani A, Le Moal M, Abrous DN: Implication of corticosteroid receptors in the regulation of hippocampal structural plasticity. Eur J Neurosci 2003, 18:3105-3111.

24. Lee CH, Yoo DY, Park OK, Park JH, Yi SS, Yoon YS, Won MH, Hwang IK: Effects of adrenalectomy and replacement therapy of corticosterone on cell proliferation and neuroblast differentiation in the rat dentate gyrus. Neurochem Res 2011, 36:1767-1775.

25. Kalminin S, Launer LJ, Stolk RP, DeJong FJ, Pols HAP, Hofman A, Breteler $M M B$, Lamberts SWJ: A prospective study of cortisol, dehydroepiandrosterone sulfate and cogntiive function in the elderly. J Clin Endocrinol Metab 1998, 83:3487-3492.

26. Van Niekerk JK, Huppert FA, Herbert J: Salivary cortisol and DHEA: association with measures of cognition and well-being in normal older men, and effects of three months of DHEA supplementation. Psychoneuroendocrinology 2001, 26:591-612.

27. Kaminska M, Harris J, Gijsbers K, Dubrovsky B: Dehydroepiandrosterone sulfate (DHEAS) counteracts decremental effects of corticosterone on dentate gyrus LTP. Implications for depression. Brain Res Bull 2000, 52:229-234.

28. Hansson AC, Sommer WH, Metsis M, Strömberg I, Agnati LF, Fuxe K: Corticosterone actions on the hippocampal brain-derived neurotrophic factor expression are mediated by exon IV promoter. J Neuroendocrinol 2006, 18:104-114.

29. Rossi C, Angelucci A, Costantin L, Braschi C, Mazzantini M, Babbini F, Fabbri ME, Tessarollo L, Maffei L, Berardi N, Caleo M: Brain-derived neurotrophic factor (BDNF) is required for the enhancement of hippocampal neurogenesis following environmental enrichment. Eur J Neurosci 2006, 24:1850-1856.

30. Burke SN, Barnes CA: Senescent synapses and hippocampal circuit dynamics. Trends Neurosci 2010, 33:153-161

31. Schimanski LA, Barnes CA: Neural protein synthesis during aging: effects on plasticity and memory. Front Aging Neurosci 2010, 2:26.

32. Hersch SM, Yi H, Heilman CJ, Edwards RH, Levey Al: Subcellular localization and molecular topology of the dopamine transporter in the striatum and substantia nigra. J Comp Neurol 1997, 388:211-227.

33. Nelson $\mathrm{N}$ : The family of $\mathrm{Na}^{+} / \mathrm{Cl}^{-}$neurotransmitter transporters. J Neurochem 1998, 71:1785-1803.
34. Asada H, Kawamura Y, Maruyama K, Kume H, Ding RG, Kanbara N, Kuzume $H$, Sanbo M, Yagi T, Obata K: Cleft palate and decreased brain gammaaminobutyric acid in mice lacking the 67-kDa isoform of glutamic acid decarboxylase. Proc Natl Acad Sci USA 1997, 94:6496-6499.

35. Xia L, Delomenie C, David I, Rainer Q, Marouard M, Delacroix H, David DJ, Gardier AM, Guilloux JP: Ventral hippocampal molecular pathways and impaired neurogenesis associated with $5-\mathrm{HT}_{1 \mathrm{~A}}$ and $5-\mathrm{HT}_{1 \mathrm{~B}}$ receptors disruption in mice. Neurosci Lett 2012, 521:20-25.

36. Thanapreedawat P, Kobayashi H, Inui N, Sakamoto K, Kim M, Yoto A, Yokogoshi $\mathrm{H}$ : GABA affects novel object recognition memory and working memory in rats. J Nutr Sci Vitaminol 2013, 59:152-157.

37. Waterhouse EG, An JJ, Orefice LL, Baydyuk M, Liao GY, Zheng K, Lu B, Xu B: BDNF promotes differentiation and maturation of adult-born neurons through GABAergic transmission. J Neurosci 2012, 32:14318-14330.

38. Lu Y, Wang Q, Melzig MF, Jenett-Siems K: Extracts of Cynomorium songaricum protect human neuroblastoma cells from beta-amyloid25-35 and superoxide anion induced injury. Pharmazie 2009, 64:609-612.

39. Liu Y, Li H, Wang X, Zhang G, Wang Y, Di D: Evaluation of the free radical scavenging activity of Cynomorium songaricum Rupr. by a novel DPPHHPLC method. J Food Sci 2011, 76:C1245-C1249.

40. Ma L, Chen G, Nie L, Ai M: Effect of Cynomorium songaricum polysaccharide on telomere length in blood and brain of D-galactose-induced senescence mice. Zhongguo Zhong Yao Za Zhi 2009, 34:1257-1260.

doi:10.1186/1472-6882-14-5

Cite this article as: Yoo et al:: Cynomorium songaricum extract enhances novel object recognition, cell proliferation and neuroblast differentiation in the mice via improving hippocampal environment. BMC Complementary and Alternative Medicine 2014 14:5.

\section{Submit your next manuscript to BioMed Central and take full advantage of:}

- Convenient online submission

- Thorough peer review

- No space constraints or color figure charges

- Immediate publication on acceptance

- Inclusion in PubMed, CAS, Scopus and Google Scholar

- Research which is freely available for redistribution 